이화여자대학교 의과대학 내과학교실, ${ }^{1}$ 진단방사선과학교실, ${ }^{2}$ 양지병원 내과

강인숙, 정지민, 류연주, 김유경 ${ }^{1}$, 이진화, 천은미, 남동길, 장중현

\title{
A Patient Presenting Purulent Discharge From Open Window Thoracostomy
}

In Sook Kang, M.D., Ji-Min Jung, M.D., Yon Ju Ryu, M.D., Yookyung Kim, M.D.', Jin Hwa Lee, M.D.,

Eun Mee Cheon, M.D., Dong Ki Nam, M.D.', Jung Hyun Chang, M.D.

Department of Internal Medicine, ${ }^{1}$ Diagnostic radiology, College of Medicine, Ewha Womans University, Seoul,

${ }^{2}$ Department of Internal Medicine, Yangi Hospital, Korea

A 73-year-old man who had undergone a right pneumonectomy and open window thoracostomy due to tuberculous empyema, presented with purulent discharge from the previous operation site. The computed tomography of the chest showed diffuse pleural thickening and a low attenuated lesion, with air bubbles in a dependent portion of the right hemithorax. These air bubbles were revealed to be due to 7 pieces of retained surgical gauze by flexible bronchoscopy. The patient showed marked clinical improvement with diminished purulent discharge after removal of the foreign bodies. (Tuberc Respir Dis 2004; 57:78-81)

Key words : Thoracostomy, Computed tomography, Foreign body.

\section{증 례}

환 자 : 홍 $\bigcirc$ 학 (남자, 73세)

주 소 : 우측 흥벽의 황색의 농성 분비물

현병력 : 상기 남환은 1998년 우측 폐결핵 및 결핵 성 농흥으로 2차례에 걸쳐 우측 폐절제술 및 흥강개구 술을 받은 과거력이 있는 분으로, 수술 후 소량의 분비 물이 계속 나와 자가로 상처를 소독해왔으나, 최근 20 일 전부터 분비물이 농성으로 변하고 양이 증가하여 노인병원에서 입원 치료하다가 호전 없어 본원으로 전원되었다.

과거력 : 결핵의 과거력외에 특이사항은 없었다.

진찰소견 : 내원 당시 활력 징후는 혈압 $90 / 60 \mathrm{~mm}$ $\mathrm{Hg}$, 호흡수 22 회/분, 맥박수 82 회/분, 체온은 $36.8{ }^{\circ} \mathrm{C}$ 이 었다. 의식은 명료하였고, 만성병색을 보였으며 피부는 건조하였다. 입술과 혀는 경도의 탈수소견을 보였다.

Address for correspondence : Jung Hyun Chang, M.D. Department of internal medicine, College of Medicine, Ewha Womans University, 911-1 MokDong, YangCheon-Ku, Seoul, 158-710, Korea Phone : 02-2650-5003 Fax : 02-2655-2076 E-mail: hs1017@ewha.ac.kr Received : Apr. 8. 2004.

Accepted : May. 28. 2004.
결막은 약간 창백하였으며, 공막에 황달은 없었다. 흥 부 청진에서 좌측 폐의 호흡음은 깨끗하였고 우측 폐의 호흡은 들리지 않았고 과다공명의 타진 소견을 보였다. 우측 측부 흥벽의 흉강개구부(직경; 약 $0.9 \mathrm{~cm}$ )로부터 악취가 나는 녹황색의 농성 분비물이 흘러나오는 소견 이 관찰되었으며, 주위 피부에 발적이 동반되었다. 복 부 및 사지 진찰에서 특이소견은 없었다.

검사 소견 : 온혈구검사에서 혈색소 $9.1 \mathrm{~g} / \mathrm{dL}$, 혈소 판수 $310,000 / \mathrm{mm}^{3}$, 백혈구수 $8,400 / \mathrm{mm}^{3}$ (호중구 $73.1 \%$ )이었고, ESR $38 \mathrm{~mm} / \mathrm{hr}, \mathrm{CRP} 10.4 \mathrm{mg} / \mathrm{dL}$ 였다. 혈청 생화학 검사상 총 칼슘 $7.8 \mathrm{mg} / \mathrm{dL}$, 인 $3.5 \mathrm{mg} / \mathrm{dL}$, BUN $5 \mathrm{mg} / \mathrm{dL}$, creatinine $0.8 \mathrm{mg} / \mathrm{dL}$ AST $12 \mathrm{IU} / \mathrm{L}$, ALT 8 IU/L ALP 157 IU/dL, 총빌리루빈 $0.5 \mathrm{mg} / \mathrm{dL}$, 총단백 $4.8 \mathrm{~g} / \mathrm{dL}$, 알부민 $2.1 \mathrm{~g} / \mathrm{dL}$ 였다. 대기중 동맥혈 가스검사는 $\mathrm{pH} 7.468, \mathrm{PaCO}_{2} 39.7 \mathrm{mmHg}, \mathrm{PO}_{2} 102.2$ $\mathrm{mmHg}, \mathrm{SaO}_{2} 96.4 \%$ 이었다. 흥강개구부의 농성 분비 물의 배양 검사에서 Pseudomonas aeroginosa가 배양 되었다.

방사선 소견 : 흉부 $\mathrm{X}^{-}$선 촬영 결과 좌폐에 결핵으 로 인한 석회화 병변들이 관찰되었으며, 이전 수술로 인해 우측의 6-7번 늑골이 일부 절제된 소견이 관찰되 었다(Fig. 1). 흥부 전산단층촬영(CT) 결과 좌폐에는 석회화 병변 및 섬유상 안정화 결핵의 소견이 관찰되 


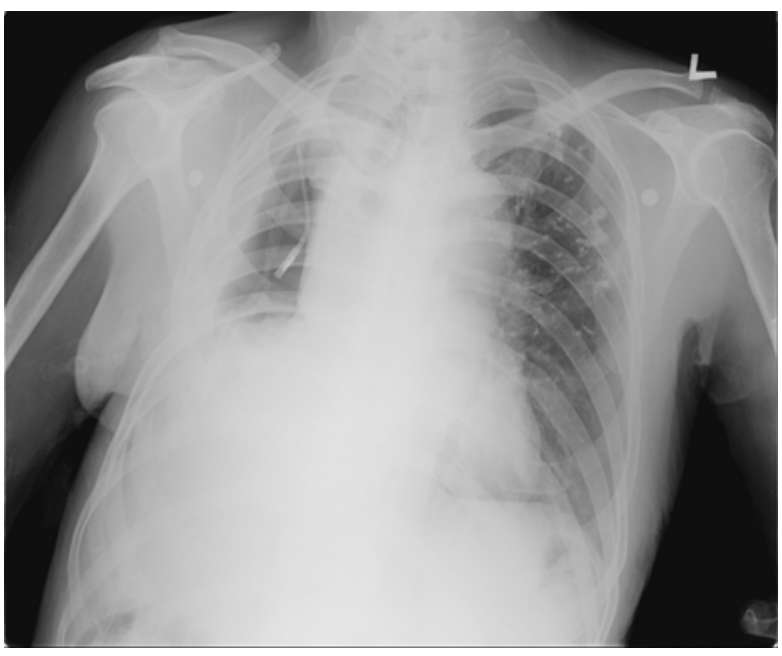

Figure 1. Chest radiograph shows pneumonectomy state, with an air-fluid level and partially resected 6th and 7 th ribs in the right hemithorax. Calcified nodules and fibrotic linear opacities are noted in the left upper lung zone.

었으며, 우폐는 폐절제술과 흥강개구술된 상태로 우측 흥곽내부에 흥막의 전반적인 비후가 관찰되었으며, 의 존부에 공기 방울들을 함유하고 있는 낮은 감쇠(low attenuation)의 병변이 관찰되었다(Fig. 2).

경 과 : 이전 수술 부위에서 녹황색의 악취가 나는 농성 분비물이 많은 양으로 계속 흘러나왔고, 주위 피 부의 발적이 동반되었다. 경험적 항생제로 cefotaxime 및 clindamy-cine을 투여하였으며, 방사선 소견으로 미루어 볼 때 이물질의 가능성을 배제할 수 없어 제 4
병일에 흥강개구부로 굴곡성 기관지내시경을 넣어 우 측 흥강내를 관찰하였다.

진단 및 추후경과 : 제 4병일에 기관지내시경을 이용 하여 우측 흥강내에 녹황색 분비물로 젖은 7장의 거즈 가 발견되어 제거하였으며(Fig. 3), 흉강 내에 고여 있 던 약 $100 \mathrm{~mL}$ 의 녹황색 분비물도 흡인 제거하였다 (Fig. 4). 배양검사 결과 위에서와 동일한 Pseudomonas aeroginosa가 자랐고 감수성 결과에 따라 항생 제를 meropenem trihydrate으로 바꿨다. 이물질 제거 후 농성 분비물이 거의 나오지 않아 퇴원하였다.

\section{고 찰}

Retained foreign body는 흔하게 발견되는 것은 아니 나, 1999년에 출판된 증례보고에 의하면, 이런 이물질 은 $80 \%$ 에서 종괴의 형태로 발견되고 3분의 4 에서 복 부나 골반부 수술 후 발견된다. 면 성분의 이물질은 빠르게 주위 염증을 유발하며, 일주일 정도가 지나면 육아종성 변화를 유발하게 된다. 또한 이물질에 감염 이 동반되면, 농양을 형성하게 되고 루(fistula)를 형성 하게 된다 ${ }^{1}$ Olnick 등은 체내에 남은 이물질을 삼출성 (exudative)과 무균적 섬유성(aseptic fibrinous)로 나 누었으며 ${ }^{2}$, 본 증례는 삼출성에 속한다고 볼 수 있다. 육아종성 변화는 없었고, 감염되어 삼출액과 흥강내 염증을 유발하고 있었다.
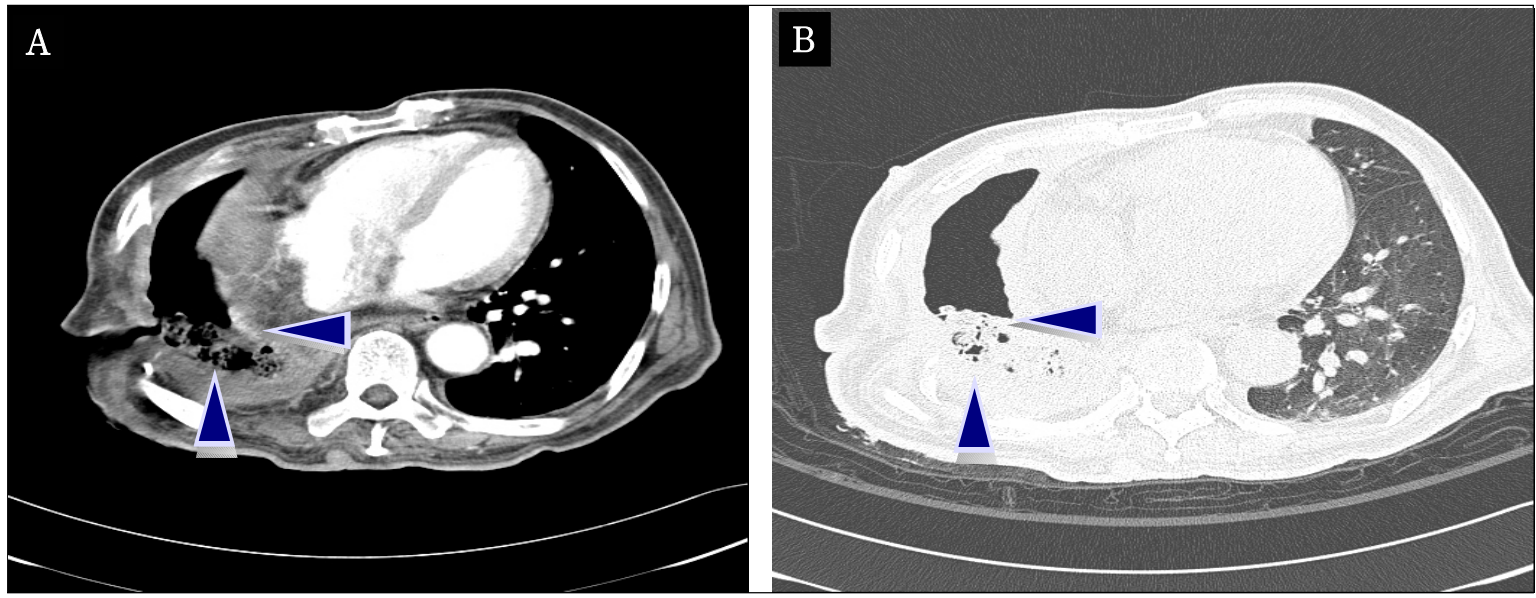

Figure 2 Contrast-enhanced CT scans (A. mediastinal window image, B. lung window image) show a mass containing multiple air bubbles (arrows) in the dependent portion of the right hemithorax. Diffuse pleural thickening and an open drainage track in the right lateral chest wall are also noted. 


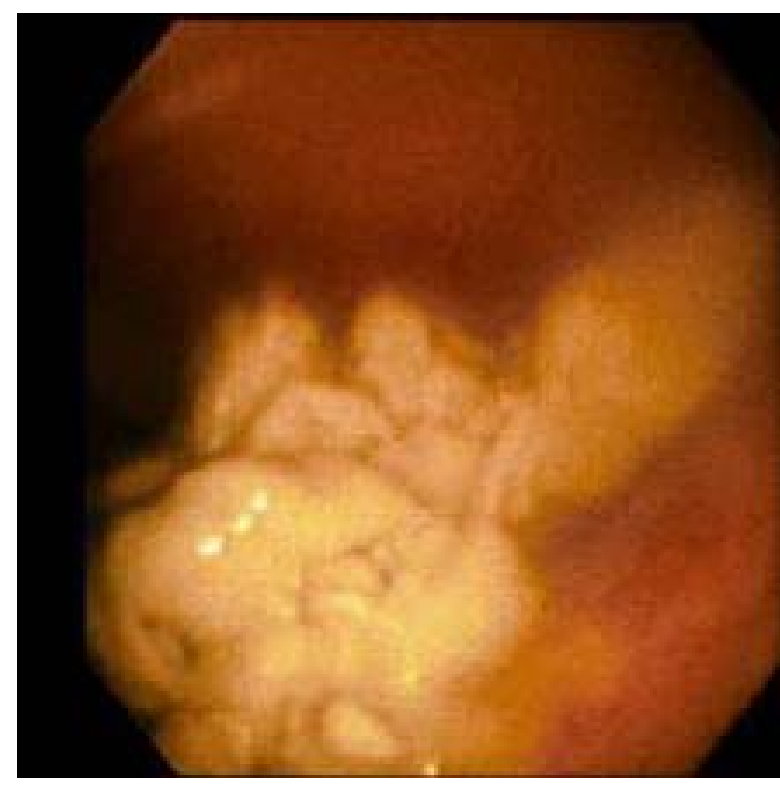

Figure 3. Retained surgical gauze was seen in thoracic cavity.

개흥술 이후에 잔여 이물질에 의한 증례에서 환자 들이 기관루에 의한 객혈을 주소로 내원하게 되는 경 우가 대부분이었으며, 방사선 검사 결과 연조직의 밀 도를 가지는 종괴, 혹은 진균종을 의심케 하는 예가 있 었다 ${ }^{3-5}$

본 질환의 진단에는 병력청취와 방사선 소견이 중 요하며, 초음파, CT 및 자기공명영상(MRI)이 사용될 수 있다 $2,6-11$.

CT에서 거즈 육아종은 주로 두꺼운 벽을 가진 둥근 종괴로 나타나며, 내부는 연조직 정도의 강도를 나타

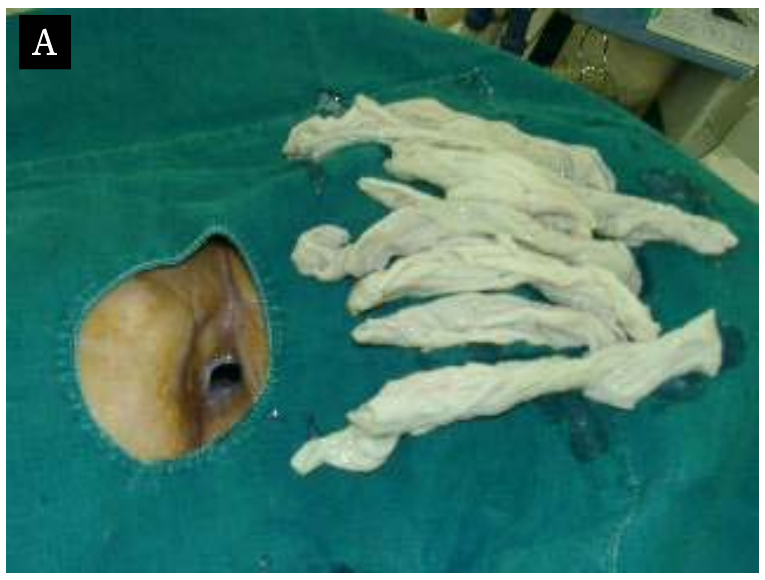

Figure 4. Seven pieces of retained surgical gauze aspirated from the right thoracic cavity(B).
내고, 반상의 석회화, 미세한 공기 방울, 섬유상 등의 다양한 음영을 가진다. MRI에서는 T1, T2 강조영상 모두에서 골수 정도의 고신호 강도를 나타낸다.

Arrive 등은 폐절제술 후 합병된 농흉의 치료를 위 해 2 차 개흉술을 시행한 환자에서 CT 검사가 합병증 과 질병 상태를 평가하는 데 도움이 되는 검사임을 제 시한 바 있다. 본 증례에서 환자의 임상 및 방사선 소 견에서 농흉을 감별할 필요가 있었으며, CT 검사 결 과 이물질을 시사하는 소견이 있어 흥강개구부를 통 해 기관지내시경과 겸자를 이용하여 흥강내 감염된 거즈 7장을 제거하였으며 환자의 경과가 호전되었다.

\section{요 약}

저자들은 흥강개구부로부터 화농성 분비물을 주소 로 내원한 만성 농흉 환자에서 흉부 CT 결과 공기 방 울을 포함한 저음영 병변으로 이물질을 의심하였고, 흥강개구부를 통해 굴곡성 기관지내시경을 삽입하여 관찰한 결과 흉강내 거즈를 발견하여 겸자로 제거한 예를 경험하였기에 문헌고찰과 함께 보고하는 바이다.

\section{참 고 문헌}

1. Vayre F, Richard P, Olliver JP. Intrathoracic gossypiboma: magnetic resonance features. Int $J$ Cardiol 1999;70:199-200.

2. Olnick HM, Weens HS, Rogers JV Jr. Radiological

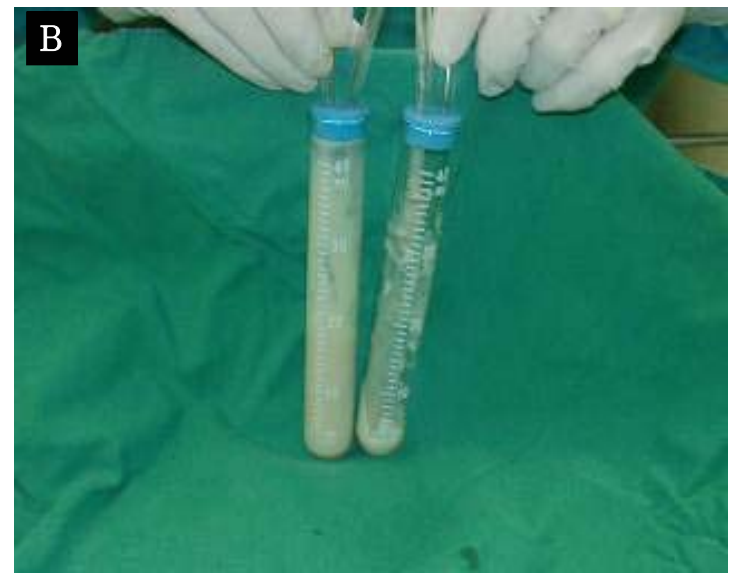

were removed(A). Green-yellowish discharge was 
diagnosis of retained surgical sponges. $\mathrm{J}$ Am Med Assoc 1955;159:1525-7.

3. Unverdorben M, Bauer U, Oster H, Kraska H, Vallbracht C. A surgical gauze appearing as a retrocardiac mass in a patient after coronary artery bypass surgery. Eur J Radiol 1999;29:273-5.

4. Nomori H, Horio H, Hasegawa T, Naruke T. Retained sponge after thoracotomy that mimicked aspergilloma. Ann Thorac Surg 1996;61:1535-6.

5. Park CS, Han SK, Choi BW, Rho YH, Kim JH, Sim YS, et al. Intrathoracic gauze granuloma. Tuberc Respir Dis. 1982;29:161-6.

6. Matsumoto S, Aikawa H, Miyake H, Mori H, Maeda $\mathrm{T}$, Nishimura $\mathrm{H}$, et al. CT and sonographic diagnosis of retained surgical sponge. Nippon lgaku Hoshasen Gakkai Zasshi 1990;50:1350-8.

7. Arrive L, Tasu JP, Kitzis M, Leseche G, Najmark D,
Duchatelle JP, et al. Open window thoracostomy, myoplasty, and epiploplasty for treatment of postpneumonectomy empyema: CT evaluation. Radiology 1994;192:177-81.

8. Lo CP, Hsu CC, Chang TH. Gossypiboma of the leg: $\mathrm{MR}$ imaging characteristics. A case report. Korean J Radiol 2003;4:191-3.

9. Hartley C, Ng KL, Jackson A. CT and MR appearance of otolaryngologic packing materials. Am J Neuroradiol 1995;16:1697-702.

10. O’Connor AR, Coakley FV, Meng MV, Eberhardt SC. Imaging of retained surgical sponges in the abdomen and pelvis. AJR 2003;180:481-9.

11. Choi BI, Kim SH, Yu ES, Chung HS, Han MC, Kim CW. Retained surgical sponge: diagnosis with CT and sonography. AJR 1988;150:1047-50. 